\title{
El desafío diagnóstico del síndrome poliuria-polidipsia
}

\author{
Coppo, J.A. \\ Cátedra de Fisiología, Facultad de Ciencias Veterinarias, UNNE, Sargento Cabral 2139, \\ Corrientes (3400), Argentina. Tel. 03783-425753. E-mail: jcoppo@vet.unne.edu.ar.
}

\begin{abstract}
Resumen
Coppo, J.A.: El desafío diagnóstico del síndrome poliuria-polidipsia. Rev. vet. 20: 2, 146153 , 2009. Se efectúa una actualización sobre el diagnóstico del síndrome poliuria-polidipsia en pequeños animales. Se revisan temas referidos a la etiología, patogenia, sintomatología, curso y opciones terapéuticas de dicho síndrome. Se resalta la importancia diagnóstica de la osmolalidad de plasma y orina, así como del esclarecimiento de las causas de proteinuria y glucosuria. Se discute la utilidad de un algoritmo diagnóstico que incluye pruebas de privación de agua y respuesta a la hormona antidiurética. Dado que este intrincado síndrome constituye uno de los más arduos desafíos de la medicina veterinaria, se enfatiza la necesidad de una constante actualización para arribar a diagnósticos más certeros.
\end{abstract}

Palabras clave: perro, gato, poliuria, polidipsia, diagnóstico.

\begin{abstract}
Coppo, J.A.: The polyuria-polydipsia syndrome: a diagnostic challenge. Rev. vet. 20:2, 146-153, 2009. A review on the diagnosis of the polyuria-polydipsia syndrome in small animals is presented. Themes referred to etiology, pathogeny, symptoms, curse, and therapeutic alternatives of this syndrome, are revised. Diagnostic importance of plasmatic and urinary osmolality determination, as well as clarification of the causes of proteinuria and glucosuria, are stood out. Utility of a diagnostic algorithm that includes water privation test and vasopressin hormone response is discussed. The necessity of a constant improvement to arrive to better diagnoses is emphasized, especially because this intricate syndrome constitutes one of the most arduous challenges in veterinary medicine.
\end{abstract}

Key words: dog, cat, polyuria, polydipsia, diagnosis.

\section{INTRODUCCIÓN}

Los pacientes que al decir de sus propietarios "orinan mucho" generalmente también tienen exacerbada la sed, configurando uno de los desafíos más complejos de la clínica de pequeños animales, cual es el esclarecimiento del síndrome poliuria-polidipsia.

En los caninos, habitualmente se considera poliuria a toda producción de orina mayor a $50 \mathrm{ml} / \mathrm{kg} / \mathrm{d}$ á, y polidipsia a la ingestión de agua mayor a $100 \mathrm{ml} / \mathrm{kg} / \mathrm{día}^{27}$ . A su vez, la orina de perros y gatos puede ser hipostenúrica (densidad 1001-1007), isostenúrica (1008-1012), mínimamente concentrada (1013-1025/1030) o hiperestenúrica (mayor de 1025/1030 en perros, mayor de $1030 / 1035$ en gatos) ${ }^{29}$.

En el síndrome poliuria-polidipsia estará afectado el equilibrio hidroelectrolítico del organismo. El riñón, mediante los procesos de filtración, secreción y resorción tubular de agua y solutos, mantiene dicho equi-

Recibido: 2 noviembre 2009 / Aceptado: 7 diciembre 2009 librio, siendo la producción de orina diluida (hipostenuria) o concentrada (hiperestenuria) los principales mecanismos para conservar la homeostasis ${ }^{13}$. Para concentrar la orina es necesario que se libere hormona antidiurética (ADH) y que los receptores de los túbulos renales respondan a ella, además del requisito de un estado de hiperosmolalidad en el intersticio medular y de por lo menos un tercio de las nefronas funcionales. La ausencia o disminución de ADH se denomina diabetes insípida central (hipofisaria, pituitaria), en tanto que la ocasionada por falta de respuesta a la hormona recibe el nombre de diabetes insípida periférica (nefrogénica) $15,22,27,29,41$.

\section{PATOGENIA}

El síndrome poliuria-polidipsia es frecuente en pequeños animales y puede deberse a anomalías de la homeostasis del agua (alteraciones de la osmolalidad plasmática y celular). En la mayoría de los casos la polidipsia es compensatoria de la poliuria, pero existen 
Tabla 1. Mecanismos inductores del síndrome poliuria-polipsia en diversas enfermedades (integrada con conceptos de varios autores $5,9,13-15,20,26,29,30,33,36,37,43$ ).

\begin{tabular}{ll}
\hline causa & mecanismo \\
\hline diabetes mellitus & hiperosmolalidad tubular (glucosa); ídem: glucosuria renal primaria \\
hipertiroidismo & hiperosmolalidad tubular (Ca, $\mathrm{P}$, catabolitos proteicos) \\
hiperaldosteronismo & hiperosmolalidad tubular (K) \\
hipoadrenocorticismo* & hiperosmolalidad tubular (urea, Na, Cl) \\
hiperadrenocorticismo & inhibición de secreción y acciones de ADH \\
hiperparatiroidismo** & hipercalcemia ( $\uparrow$ osmolalidad plasma, estimulación sed, inhibición ADH) \\
diabetes insípida hipofisaria & ausencia / deficiencia de ADH \\
diabetes insípida nefrogénica & falla receptores tubulares de ADH (acuaporina AQP2) \\
poliuria psicogénica & psicopatía (no confundir con polidipsia causada por fiebre y dolor) \\
piómetra & falla receptores tubulares de ADH por toxinas bacterianas $(E$. coli) \\
fallo hepático & $\downarrow$ hipertonicidad medular renal ( $\downarrow$ urea), no remoción de angiotensina (hiperosmolalidad tubu- \\
lar por $\uparrow$ de resorción de agua) \\
insuf. renal aguda (poliúrica) & compensación de la incapacidad para concentrar, ante la hiperosmolalidad tubular (provocada \\
& por Na, Cl, P, K). \\
insuf. renal crónica (poliúrica) & compensación de la incapacidad para concentrar, ante la hiperosmolalidad tubular (provocada \\
& por proteínas y otros metabolitos). \\
\hline
\end{tabular}

insuf.: insuficiencia; $\uparrow$ aumento; $\downarrow$ disminución; *déficit de cortisol y aldosterona; $* *$ en fase avanzada se agrega incapacidad para concentrar orina por fallo renal (calcinosis).

polidipsias primarias con poliuria compensatoria. Las polidipsias primarias pueden ser psicogénicas (compulsivas por ansiedad, aburrimiento y otras causas no orgánicas), u ocurrir por tumor, trauma o inflamación del hipotálamo (irritación neuronal), aumentos de renina-angiotensina y también por hipercalcemia, fiebre y dolor ${ }^{29}$.

El estado de poliuria-polidipsia puede deberse a numerosas causas, como diabetes mellitus y diabetes insípida (central o periférica), hiperadrenocorticismo (Cushing), hipoadrenocorticismo (Addison), estrés (especialmente en gatos), inducción por drogas, glucosuria renal primaria, proteinuria, falla renal primaria, falla hepática, polidipsia sicogénica y otras enfermedades. Determinar la causa de la poliuria implica integrar los síntomas con el estado de hidratación y los resultados de las determinaciones de glucemia, glucosuria, uremia y densidad urinaria, así como de las pruebas de privación de agua y respuesta a la $\mathrm{ADH}^{5,9,20}$.

El volumen de líquido corporal y la osmolalidad dependen del balance entre ingestión y pérdida de agua, lo cual está regulado por mecanismos neuroendocrinos y renales. La osmolalidad del líquido extracelular depende principalmente de la concentración de sodio del medio interno ${ }^{13,43}$. Aumentos de la osmolalidad provocarán sed y reducción del volumen urinario al aumentar la liberación de $\mathrm{ADH}$. La resorción de agua depende de la existencia de una elevada hiperosmolalidad en la medula renal $(\mathrm{Na}$, urea). Algunos procesos producen poliuria-polidipsia debido a la pérdida del gradiente osmótico del intersticio medular renal ("medullary washout" por déficit de urea, Na y K) ${ }^{29,33,36}$.

Las diuresis osmóticas se deben a la presencia de una concentración tubular de solutos tan alta que supera la capacidad de resorción tubular e impide la reabsorción del agua (a pesar de la presencia de ADH) ${ }^{13,26}$.
Algunos de tales solutos, así como las enfermedades de base y sus mecanismos de acción, son compendiados en la Tabla 1. Las poliurias primarias pueden deberse a diuresis osmóticas como las causadas por diabetes mellitus, glucosuria renal primaria, diuresis post-obstructivas (urea) y otras, así como a diabetes insípida central (deficiencia total o parcial de $\mathrm{ADH}$, idiopática o provocada por neoplasia, defecto congénito o trauma) $29,30,37$. Las insuficiencias renales reconocen orígenes como nefritis agudas o crónicas, glomerulonefritis, nefrosis, amiloidosis renal, hiperparatiroidismo (calcinosis renal por hipercalcemia), cetosis e intoxicación por litio (disminuye sensibilidad de receptores de ADH en túbulos) ${ }^{2,11,15,16,33,36}$. El síndrome poliuria-polidipsia también puede ocurrir por iatrogenia medicamentosa, diuréticos (furosemina inhibe resorción de $\mathrm{NaCl}$ en asa de Henle provocando hipotonicidad medular e hipertonicidad tubular con diuresis osmótica) ${ }^{36} \mathrm{y}$ por intoxicación con etilenglicol ${ }^{10}$.

\section{DIAGNÓSTICO}

Para establecer la etiología del estado de poliuriapolidipsia se deben solicitar determinaciones séricas de glucosa, calcio, potasio y sodio, así como urinarias (volumen $24 \mathrm{~h}$, osmolalidad y electrolitos). La prueba de restricción de agua diferencia polidipsia primaria de diabetes insípida. Para distinguir entre diabetes insípida neurogénica parcial y polidipsia primaria o hidratación excesiva, debe determinarse la osmolalidad plasmática y urinaria, así como la concentración de ADH. Cuando la osmolalidad plasmática es alta y los niveles sanguíneos de ADH son indetectables, seguramente existe una diabetes insípida completa ${ }^{20,28,36}$.

Si los niveles plasmáticos de ADH son detectables pero inferiores a los esperados para la hiperosmola- 
Tabla 2. Cambios de la osmolalidad plasmática y urinaria según la enfermedad.

\begin{tabular}{cccl}
\hline $\begin{array}{c}\text { osm. } \\
\text { plasma }\end{array}$ & $\begin{array}{c}\text { osm. } \\
\text { orina }\end{array}$ & ADH & afección \\
\hline A & - & D & diabetes insípida central completa \\
A & - & N-D & diabetes insípida central parcial \\
N & - & N & diab. insíp. nefrogénica o polidipsia 1ria \\
- & D & N & diabetes insípida nefrogénica \\
- & N & N & polidipsia primaria \\
\hline
\end{tabular}

osm.: osmolalidad; A: aumentada; D: disminuida; N: normal; diab. insíp.: diabetes insípida; 1ria: primaria.

lidad plasmática, se tratará de una diabetes insípida central parcial. Si la concentración de ADH y la osmolalidad plasmática son normales, el paciente padecerá de polidipsia primaria o diabetes insípida nefrogénica. Para distinguir entre estas dos últimas entidades se debe examinar la relación entre ADH plasmática y osmolalidad urinaria. Se diagnostica diabetes insípida nefrogénica cuando la osmolalidad urinaria es muy baja respecto a la concentración de $\mathrm{ADH}$, mientras que se diagnostica polidipsia primaria si la relación es adecuada (Tabla 2) ${ }^{16,17,36}$.

Como se advierte, las aplicaciones clínicas de la osmometría en medicina veterinaria son invalorables. En ciertos casos quizás no pueda justificarse económicamente la compra de un osmómetro (Figura 1), pero debe tenerse en cuenta su disponibilidad en centros médicos y laboratorios clínicos. En una época donde las técnicas bioquímicas se están usando más y más, no puede obviarse el conocimiento de la osmolalidad del suero y la orina. La determinación de la osmolalidad es una prueba simple, rápida y económica, de gran utilidad para elucidar los desórdenes de los fluidos corporales y sus electrolitos. El panorama se completa con la medición sérica de los electrolitos, urea y glucosa. La osmometría provee el más exacto método para medir la capacidad del riñón para concentrar la orina y es particularmente valiosa en la evaluación de pacientes poliúricos y proteinúricos ${ }^{19}$.

\section{OSMOLALIDAD DEL PLASMA}

La osmolalidad de una solución es el número de osmoles de soluto por $\mathrm{kg}$ de solvente, en tanto que osmolaridad es el número de osmoles de soluto por litro de solución. Dado que el 93\% del plasma sanguíneo es agua, la diferencia entre osmolalidad y osmolaridad es ínfima. Recuérdese que un osmol (medida de presión osmótica) equivale a un mol (peso molecular expresado en gramos) dividido por el número de partículas que ioniza ${ }^{13}$.

La osmolalidad del suero se debe principalmente a su contenido en electrolitos, moléculas orgánicas y coloides, estos últimos (proteínas) participan escasamente porque no obstante encontrarse presentes con una masa considerable, su concentración molal es baja debido a su alto peso molecular (menor número de partículas). El laboratorio determina la osmolalidad utilizando la crioscopía (osmómetro), aunque el valor también puede obtenerse por cálculo, conociendo las concentraciones séricas o plasmáticas de algunos de sus componentes ${ }^{15,26}$, aplicando la fórmula:

$$
\begin{gathered}
\text { osmolaridad } \\
\text { del suero }
\end{gathered}=2\left(\mathrm{Na}^{+} \text {meq/L }+\mathrm{K}^{+} \text {meq/L) }+\frac{\text { Glucosa mmol/L }}{18}+\frac{\text { BUN mmol/L }}{2,8}\right.
$$

Para ejemplificar, veamos el caso de un perro al que se le efectuaron determinaciones plasmáticas de sodio $(140 \mathrm{meq} / \mathrm{l})$, potasio $(5 \mathrm{meq} / \mathrm{l})$, glucosa $(1 \mathrm{~g} / \mathrm{l}) \mathrm{y}$ urea $(0,33 \mathrm{~g} / \mathrm{l})$. En primer lugar habrá que transformar el valor de glucosa $(100 \mathrm{mg} / \mathrm{dl})$ a unidades SI (Sistema Internacional de Unidades), multiplicando por 0,055. El resultado será de $5,5 \mathrm{mmol} / \mathrm{l}$, que al ser dividido por 18 dará 0,3 . Luego habrá que transformar el valor de urea $(33 \mathrm{mg} / \mathrm{dl})$ a BUN (nitrógeno ureico) multiplicando por 0,46 . El resultado $(15 \mathrm{mg} / \mathrm{dl})$ deberá convertirse a unidades SI multiplicando por 0,357 y este producto (6 mmol/l) deberá dividirse por 2,8. La cifra final será 2. Resolvamos ahora la fórmula anterior:

$$
2(140+5)+0,3+2=292 \operatorname{mosm} / 1
$$

Nótese la escasa participación de glucosa y urea en la osmolalidad plasmática total del perro sano. Sin embargo, si se tratara de un canino gravemente urémico, con $5 \mathrm{~g} / 1$ de urea en plasma, los cálculos darían: 500 $\mathrm{mg} / \mathrm{dl} \times 0,46=230 \mathrm{mg} / \mathrm{dl}$ de BUN x 0,357 = $82 \mathrm{mmol} / 1$ $\div 2,8=29$. Si con esta cifra resolviéramos la fórmula, comprobaríamos un importante aumento de la osmolalidad:

$$
2(140+5)+0,3+29=320 \operatorname{mosm} / 1
$$

La osmolalidad plasmática es de 250-310 mosm/1 en el perro y de $280-310 \mathrm{mosm} / \mathrm{l}$ en el gato. Este parámetro aumenta en las insuficiencias renales (exceso de urea), en la diabetes mellitus (exceso de glucosa) y en las deshidrataciones en las cuales la pérdida de agua sea superior a la pérdida de solutos, en cuyo caso el grado de hiperosmolalidad será di-

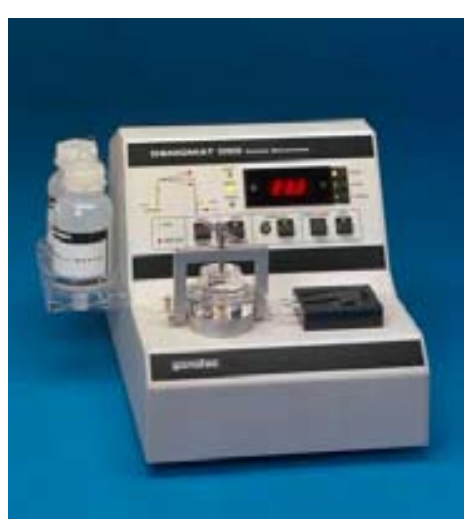

Figura 1. Osmómetro. rectamente proporcional a la hipernatremia. La hiperosmolalidad también puede ser causada por sustancias exógenas (iatrogenia) ${ }^{15,37}$.

Por el contrario, la hiposmolalidad puede ocurrir en estados de sobrehidratación, hiponatremia y secreción excesiva ("inadecuada") de $\mathrm{ADH}$. La fórmula anteriormente descripta puede ayudarnos a entender la hiponatremia de la diabetes mellitus, dado que la hiperglucemia tiende a tornar hiperosmolal el medio inter- 
no y ello provoca pérdida compensatoria de sodio del líquido extracelular por orina, causando disminución sérica del catión ${ }^{15,20,43}$.

\section{OSMOLALIDAD DE LA ORINA}

Tener en cuenta que este parámetro (dependiente del número de partículas) no es equivalente a la densidad (comparación de masas). La osmolalidad urinaria es útil para valorar la capacidad del riñón en la tarea de concentrar y diluir la orina. En el perro es de $1080 \pm$ $350 \mathrm{mosm} / 1$ (500-1200, 200-2000 mosm/l según otros) $\mathrm{y}$ en el gato de 1000-2200 mosm/1 (500-1200, hasta $2500 \mathrm{mosm} / 1$ para otros). En la insuficiencia renal crónica de perros y gatos, la osmolalidad desciende hasta ser semejante a la del plasma $( \pm 300 \mathrm{mosm} / \mathrm{l})$. En las poliurias puede disminuir hasta $50 \mathrm{mosm} / 1^{15,26,33}$.

Dentro de las numerosas causas de arrastre osmótico y pérdida de agua a través de las vías urinarias, por su frecuencia se destacan dos de ellas, las proteinurias y glucosurias.

\section{PROTEINURIAS}

En su gran mayoría son albuminurias, normales en el recién nacido, estro y pre-parto. Se determinan mediante tiras reactivas, fotocolorimetría, reacción de Heller $\left(\mathrm{HNO}_{3}\right)$, calor (turbidez) o por electroforesis. En la Figura 2 se muestran corridas electroforéticas realizadas en orina de caninos con diferentes afecciones. Las proteinurias extra-renales pueden deberse a procesos inflamatorios y/o hemorrágicos de las vías urinarias, cistitis, insuficiencia cardíaca congestiva y neoplasias. En el plasmocitoma (mieloma múltiple) puede aparecer una globulina denominada proteína de Bence-Jones, un dímero de cadenas livianas de $\operatorname{IgG}$ o IgA monoclonales, que filtra por el glomérulo debido a su bajo peso molecular (44.000 D) $9,15,16,26$.

Las proteinurias glomerulares se deben a un anormal aumento de la filtración proteica. En los daños glomerulares leves solo filtran albúminas; en glomerulopatías graves también lo hacen otras proteínas de mayor tamaño. Las proteinurias glomerulares ocurren en glomerulopatías inmunomediadas, amiloidosis renal, lupus sistémico y nefrosis lipoide. Acompañadas por

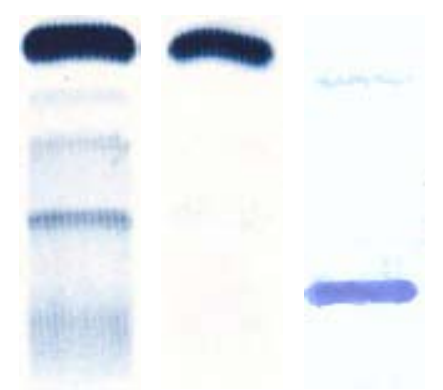

Figura 2. Izquierda: proteinuria (daños glomerular y tubular). Centro: albuminuria (daño glomerular). Derecha: proteína de Bence-Jones (mieloma). hematuria y piuria señalan la presencia de glomerulonefritis inflamatoria o lesiones de vías urinarias. Al producirse el escape de antitrombina-III $(62.0000 \mathrm{D})$ se pierde el freno de la activación de la trombina, pudiendo aparecer trombosis. Las proteinurias tubulares, menos frecuentes, obedecen a fallas de resorción y sobrevienen por acidosis tubular renal, pielonefritis, nefritis intersticiales, poliquistosis y Síndrome de Fanconi (ver más adelante). Frecuentemente acompañan a las proteinurias glomerulares ${ }^{15,16,37}$.

En cuanto a su magnitud, las pérdidas proteicas pueden ser cuantiosas, moderadas o escasas. Pérdidas cuantiosas (mayores de $4 \mathrm{~g} /$ día) configuran el "síndrome nefrótico" y son causadas por glomerulonefritis agudas graves (con cilindruria), nefroesclerosis, amiloidosis, lupus sistémico, trombosis de vena renal, intoxicaciones (por plomo, mercurio, arsénico, fósforo, sulfas, éter, fenol y trementina). Las pérdidas moderadas $(0,4-4 \mathrm{~g} /$ día) ocurren en inflamaciones e infecciones del riñón y vías urinarias, glomerulonefritis crónicas, nefropatías tóxicas, pre-eclampsia e hiperadrenocorticismo. Las pérdidas escasas (menores de $0,4 \mathrm{~g} /$ día) son propias de la fase de curación de las glomerulonefritis, tubulopatías, poliquistosis renal, prostatitis y lesiones del tracto urinario bajo. Pérdidas muy escasas (benignas) suelen aparecer por estrés, cólicos, convulsiones, dieta hiperproteica, fiebres, excesiva exposición al calor o frío y por ejercicio agotador ${ }^{15,26,30}$.

\section{GLUCOSURIAS}

Se detectan a través de las reacciones colorimétricas de Benedict o Fehling, por espectrofotometría (técnica enzimática) o mediante tiras reactivas. Las glucosurias fisiológicas aparecen por efecto del ejercicio, miedo, dieta hiperglucídica, fármacos (adrenalina, glucocorticoides, dextrosa y anestésicos); algunos autores agregan causas como asfixia, shock y convulsiones. Las glucosurias extra-renales responden a hipoinsulinemias (diabetes mellitus, pancreatitis agudas y crónicas) e hiperglucemias (hipertiroidismo, hiperadrenocorticismo, hiperpituitarismo, ciertas hepatopatías crónicas), así como a la hipervitaminosis C. Las glucosurias renales se presentan en las nefritis que cursan con disminución del umbral renal para la glucosa y también en algunas nefrotoxicosis. Existe una "glucosuria renal primaria" atribuible a falla tubular de la resorción del monosacárido ${ }^{9,15,37}$.

Cuando una glucosuria normoglucémica se acompaña de aminoaciduria y aumento de la excreción urinaria de fosfato, a veces también de sodio, potasio, calcio, bicarbonato, proteínas, vitaminas y ácido úrico (analitos que paralelamente están disminuidos en plasma), se habrá configurado el Síndrome de Fanconi ("aminodiabetes"), una incapacidad de los túbulos proximales para resorber dichos compuestos. El trastorno cursa con poliuria, polidipsia, enflaquecimiento, osteomalacia, astenia (hipokalemia), urolitiasis y acidosis sistémica, con trastornos metabólicos conducentes a la insuficien- 
cia renal urémica. En su etiología se citan intoxicaciones por plomo, cobre, mercurio, cadmio, azatioprina, gentamicina y tetraciclina utilizada después de la fecha de vencimiento. A veces es secundario a la cistinosis, amiloidosis y mieloma múltiple. Es hereditario en la raza Basenji, quizás también en Shetland, Schnauzer miniatura, Scottish Terrier y Elkhound. En gatos puede provocar obstrucción urinaria ${ }^{15,26,43}$.

\section{ALGORITMO DIAGNÓSTICO}

En la Figura 3 se consigna un algoritmo diagnóstico aplicable al síndrome poliuria-polidipsia del perro, que excluye pacientes con hipercalcemia, piómetra y tratamientos hormonales. Al indicar glucosuria, el urianálisis inicial puede conducir al diagnóstico de glucosuria renal primaria (con normoglucemia) o diabetes mellitus, hiperadrenocorticismo, estrés o acción de fármacos (con hiperglucemia). La ausencia de glucosuria amerita investigar la densidad de la orina: si es mayor de 1030 se trata de una diuresis osmótica por proteinuria u otras sustancias. La densidad menor de 1030 obliga a averiguar el estado del nitrógeno no proteico del suero (NNP). Cuando éste aparece elevado deberán efectuarse las determinaciones plasmáticas de sodio y potasio.

Nótese que este algoritmo preferencia la densidad por sobre la osmolalidad, generando la necesidad de valorar la relación entre los dos principales cationes del medio interno (Na:K). Si la relación $\mathrm{Na}: \mathrm{K}$ es mayor de
27 indicará insuficiencia renal poliúrica primaria, pero si es menor de 27 puede deberse a una insuficiencia renal por hipoadrenocorticismo (deficiencias de cortisol y aldosterona), donde los aumentos séricos de potasio, urea y creatinina coexistirán con las disminuciones séricas de sodio y glucosa.

Cuando el NNP sérico haya resultado normal corresponde verificar el estado de hidratación. Pacientes deshidratados cuya relación $\mathrm{Na}: \mathrm{K}$ sea mayor de 27 deberán someterse a la prueba de respuesta a la ADH (ver más adelante). Si la relación $\mathrm{Na}: \mathrm{K}$ es menor de 27 puede tratarse de un hipoadrenocorticismo o efectos de la dieta hiposódica. Cuando la deshidratación está ausente un camino consiste en realizar el hepatograma, mediante el cual los aumentos de alanin aminotransferasa ALT indicarán daño hepatocelular y las elevaciones de fosfatasa alcalina ALP señalarán colestasis o hiperadrenocorticismo (hipercortisolemia e hiperglucemia). Cuando las actividades de dichas enzimas hayan resultado normales, puede investigarse la existencia de hipertiroidismo mediante eventuales aumentos séricos de $\mathrm{T}_{3} \mathrm{y} \mathrm{T}_{4}$.

Otro camino en pacientes no deshidratados consiste en efectuar la prueba de privación de agua. Densidades superiores a 1030 sugieren polidipsia psicogénica y densidades menores a 1030 habilitan la realización de la prueba de respuesta a la ADH. Si el animal concentra la orina puede estar afectado por hiperadrenocorticismo o diabetes insípida central. Si la orina continúa diluida es factible realizar un clearance de creatinina, cuya dis-

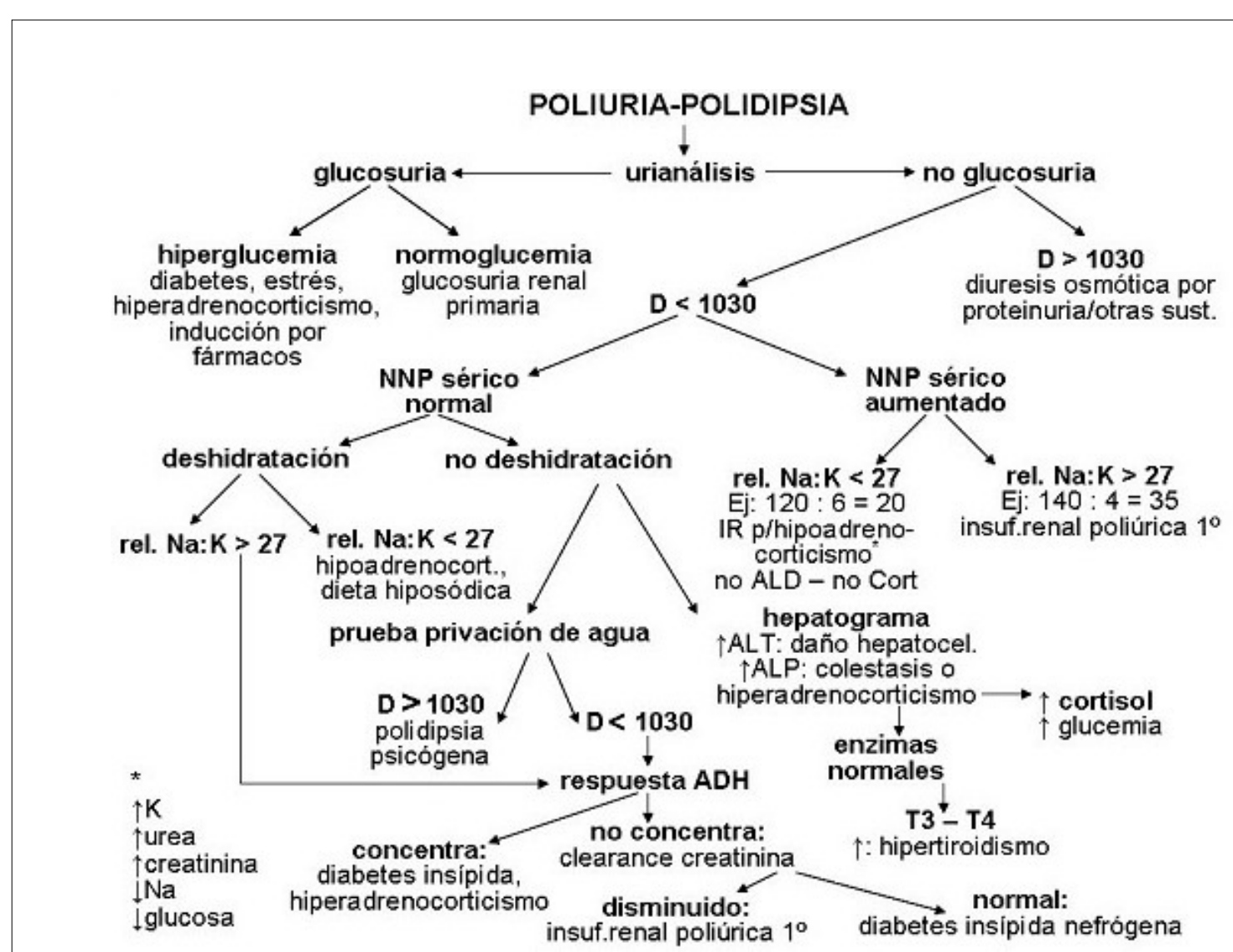

Figura 3. Algoritmo diagnóstico del síndrome poliuria-polidipsia (modificado de Polzin \& Osborne ${ }^{30}$ ). 
minución confirmará una insuficiencia renal poliúrica primaria y cuyo aumento indicará la probabilidad de la existencia de una diabetes insípida periférica ${ }^{15,30}$.

En la opinión del autor de esta revisión, el algoritmo descrito es uno de los más claros y entendibles. $\mathrm{Su}$ complejidad señala sin lugar a dudas la ímproba tarea de elucidar el diagnóstico del síndrome poliuria-polidipsia, implicando el insumo de una considerable cantidad de horas de trabajo, el requerimiento de un laboratorio capaz de efectuar determinaciones enzimáticas y hormonales y la disponibilidad de drogas y reactivos específicos, amén de un propietario capaz de afrontar el costo de tales prácticas. El panorama se complica aún más porque la investigación científica aporta día a día nuevas causas y mecanismos capaces de provocar el síndrome poliuria-polidipsia.

\section{APORTES DE LA INVESTIGACIÓN}

Además de las causas antemencionadas, el síndrome poliuria-polidipsia puede aparecer como consecuencia de enfermedades infiltrativas (sarcoidosis, histiocitosis, amiloidosis), aporte exógeno de $\mathrm{NaCl}$, bicarbonato, otros diuréticos, medios de contraste, nicotina, etanol, clonidina, demeclociclina, fenitoína, primidona, fenobarbital, fluoruros, metoxifluorano, cisplatino, ácido etacrínico, exceso de proteína dietaria, hipercatabolismo proteico, infecciones (tuberculosis, meningitis, encefalitis), neoplasias (primarias y secundarias), mieloma múltiple, lesiones postraumáticas, neurocirugía, aumento de la excreción de aniones orgánicos (cetoácidos) y otras ${ }^{17,36}$.

En medicina humana se ha descubierto que la lesión túbulo-intersticial de la nefropatía diabética es causada por el daño celular inducido por la hiperglucemia pero también por el aumento de la glucosilación proteica. La poliuria por arrastre osmótico de solutos jugaría un papel importante en la iniciación y progresión de las lesiones túbulo-intersticiales ${ }^{42}$. Mecanismos adaptativos renales han demostrado ser capaces de reducir el riesgo de urolitiasis por hipercalciuria, a través de la acidificación de la orina y el aumento de la excreción urinaria de calcio y fosfato mediante una profusa poliuria ${ }^{32}$. La amilorida se reveló capaz de bloquear la captación de litio existente en los fármacos psicotrópicos capaces de provocar diabetes insípida nefrogénica ${ }^{2}$.

En roedores se ha demostrado que el bloqueo de los receptores de angiotensina genera una diabetes insípida nefrogénica resistente a la $\mathrm{ADH}$, con abundante poliuria; ello demuestra una importante interacción ADH-angiotensina para lograr máximas concentraciones urinarias ${ }^{34}$. A determinadas dosis, la anfotericina provoca daño renal en ratones con aumentos de urea y creatinina plasmáticas, que al aclararse provocan poliuria y deshidratación. La actividad urinaria de lactato dehidrogenasa LDH se reveló como una sensible indicadora de la nefrotoxicidad por anfotericina ${ }^{40}$.

Experiencias con ratones demostraron que la pérdida de receptores renales de vitamina $\mathrm{D}$ provoca intensa poliuria, por un mecanismo aún desconocido. La osmolalidad urinaria permanece normal y la excreción de sal es alta. La aplicación de un antagonista del receptor de angiotensina normalizó la ingestión de agua y el volumen de orina ${ }^{24}$.

Experimentalmente, el aumento de la filtración de proteínas plasmáticas a través del glomérulo produce intensa poliuria en ratas ${ }^{25}$. Se han descubierto drogas que incrementan la expresión del gen de acuaporina 2 en el riñón de un modelo experimental de rata poliúrica. Dicha acuaporina, al ser estimulada por $\mathrm{ADH}$, promueve la resorción tubular de agua ${ }^{6,14}$. Un modelo animal de diabetes insípida nefrogénica fue obtenido en ratas mediante la intoxicación con litio, el cual produce una reducción de la mencionada acuaporina ${ }^{38}$.

\section{CASUÍSTICA EN ANIMALES}

La gran cantidad de reportes recientes sobre investigaciones tendientes a esclarecer las causas, mecanismos y tratamientos del síndrome poliuria-polidipsia en animales domésticos son elocuentes respecto de la importancia que reviste el tema. Las etiologías más comunes comunicadas en pequeños animales fueron insuficiencia renal crónica, pielonefritis, hiperadrenocorticismo e hipercalcemia; determinar el origen de este síndrome generalmente es una tarea larga, tediosa, confusa y a veces no conduce al retorno de la salud del paciente ${ }^{28}$.

En caninos y felinos, la poliuria por hipercalcemia reconoce orígenes como el fallo renal crónico, neoplasias, intoxicaciones, nocardiosis y otros ${ }^{21}$. La causa de aparición del síndrome poliuria-polidipsia en un gato de 5 meses de edad fue una displasia renal diagnosticada por ultrasonografía (anomalías glomerulares y tubulares), entidad que cursó con cambios bioquímicos compatibles con un fallo renal crónico ${ }^{1}$.

Un perro con hidrocefalia padeció simultáneamente poliuria, polidipsia, severas hiponatremia e hipoosmolalidad sérica, datos que condujeron al diagnóstico del síndrome de secreción inadecuada (excesiva) de hormona antidiurética; la restricción de agua condujo al alivio de los síntomas ${ }^{35}$. Entre las numerosas etiologías del síndrome poliuria-polidipsia en animales, destacan por su importancia entidades como la polidipsia psicogénica y la diabetes insípida en sus variedades central y nefrogénica ${ }^{17}$.

En perros y gatos en crecimiento el principal disturbio capaz de provocar poliuria y polidipsia es el desbalance del metabolismo del agua, principalmente por diabetes mellitus y diabetes insípida ${ }^{18,23}$. Llamativamente, en una cabra se diagnosticó diabetes mellitus tipo I; los síntomas principales fueron polidipsia y poliuria, esta última debida al arrastre osmótico de agua causado por glucosuria y cetonuria ${ }^{3}$.

En los últimos años se han incrementado los reportes de gatos con síndrome poliuria-polidipsia causado por hiperadrenocorticismo (hiperglucemia, glucosuria) 7,28 . La poliuria-polidipsia de un felino con diagnóstico de diabetes mellitus resultó finalmente haber sido cau- 
sada por un carcinoma de corteza adrenal que, en lugar de cortisol segregaba progesterona; el hallazgo refrenda la similitud sintomática entre el hipercortisolismo y el hiperprogesteronismo ${ }^{31}$.

Recientemente se reportó una serie de casos de fallo renal poliúrico (hiperazotemia, hiperfosfatemia) en perros y gatos alimentados con pellets balanceados contaminados con melamina y ácido cianúrico, tóxicos provenientes del gluten de trigo que se añaden clandestinamente al alimento para aumentar su nivel proteico ${ }^{4}$. En una de dichas publicaciones se reportan 70 historias clínicas de gatos intoxicados con alimentos contaminados con melamina y ácido cianúrico, con poliuria-polidipsia, azotemia, necrosis tubular y cristaluria ${ }^{8}$. Perros y gatos padeciendo torsión de algún lóbulo hepático (lateral izquierdo, medial derecho o caudal), mostraron síntomas de poliuria y polidipsia, cuyo origen no fue aclarado ${ }^{39}$.

Aproximadamente la mitad de los perros con diabetes insípida central son gerontes y padecen tumores pituitarios. A su vez, la diabetes insípida periférica puede ser primaria (insensibilidad renal para la $\mathrm{ADH}$, muy rara) o secundaria a alteraciones capaces de interferir (temporalmente) la acción tubular de $\mathrm{ADH}$, tales como ciertos fármacos y dietas, pérdida de la osmolalidad medular renal, hipercalcemia, pielonefritis, piómetras (toxinas bacterianas interfieren la acción ADH en túbulos, especialmente E. Coli), insuficiencia renal (la cual provoca también hiperazotemia, hiperfosfatemia y proteinuria), hipokalemia (por diarreas o fluidoterapia), hipoadrenocorticismo (la disminución de aldosterona genera aumento de excreción de $\mathrm{K}$, además se elevan en sangre: urea, creatinina, fosfatos y calcio), hiperadrenocorticismo (hiperglucemia, proteinuria por daño glomerular, inhibiciones de ADH y TSH afectando el nivel de $\mathrm{T}_{4}$ ), hipertiroidismo (azotemia, aumento de excreción de fosfatos), feocromocitoma (aumento de catecolaminas, hiperglucemia), acromegalia (aumento de somatotrofina $\mathrm{GH}$, hiperglucemia), hiperprogesteronemia (estimula el aumento de GH mamaria, hiperglucemia), insuficiencia hepática (la disminución de urea provoca pérdida de tonicidad medular) y otras ${ }^{29}$. La hipercalcemia a veces es producida por una hipervitaminosis D iatrogénica ${ }^{11}$.

\section{OPCIONES TERAPÉUTICAS}

La diabetes insípida central responde al tratamiento con ADH exógena. Fármacos como la clorpropamida, clorfibrato y carbamazepina aumentan la sensibilidad tubular a la $\mathrm{ADH}$, por lo cual pueden ser efectivos en el tratamiento de diabetes insípida central incompleta. En los casos de diabetes insípida nefrogénica secundaria a fármacos corresponde considerar la suspensión de la medicación nociva. Muchos casos de diabetes insípida nefrogénica y central son leves y no requieren tratamiento; el mecanismo de la sed es la principal defensa contra la deshidratación, por lo cual nunca se debe restringir la ingesta de líquidos en estos pacientes. La insulina estará indicada en las hiperglucemias. En las poliurias secundarias a trastornos electrolíticos se impone la corrección de la alteración de base (especialmente de las hipokalemias). Las prostaglandinas han demostrado antagonizar el efecto hidroosmótico de la $\mathrm{ADH}$, mientras que los inhibidores de la prostaglandinsintetasa aumentan el efecto biológico de la hormona. Así, la resistencia al efecto de la ADH en la diabetes insípida nefrogénica puede ser superado en parte con la administración de antiinflamatorios no esteroideos (indometacina). El litio inhibe la reabsorción de agua mediada por $\mathrm{ADH}$ en el túbulo colector y la amilorida antagoniza esta inhibición, también inhibe la captación tubular e intracelular de litio, por lo que es usada en las diabetes insípidas nefrogénicas producidas por litio ${ }^{36}$.

Por el peligro de deshidratación, el pronóstico de la diabetes insípida nefrogénica es reservado a grave. En cambio, es favorable a reservado en la diabetes insípida central, incluso sin tratamiento, siempre que el animal disponga de suficiente agua ${ }^{17}$.

\section{COLOFÓN}

La base del diagnóstico clásico sigue siendo "ver, palpar y escuchar", pero los conceptos vertidos en páginas anteriores señalan que a veces ello no es suficiente, debiendo recurrirse al laboratorio para esclarecer y objetivar el diagnóstico. El estudio retrospectivo del accionar de un servicio de análisis clínicos durante los últimos 25 años (unos 15.000 animales examinados, 50\% caninos), reveló que las afecciones más frecuentes fueron las nefrourinarias, seguidas por las hepatobiliares, endocrinas, inflamatorias, infecciosas, metabólicas, inmunes, tumorales, tóxicas y otras ${ }^{12}$, muchas de las cuales pueden cursar con el síndrome poliuria-polidipsia.

La utilidad del diagnóstico complementario quedó evidenciada al comprobarse que alrededor del $30 \%$ de los diagnósticos presuntivos iniciales debieron modificarse en función a los hallazgos de laboratorio. El correcto diagnóstico y un acertado tratamiento harán emerger en el veterinario la satisfacción personal de haber hecho lo mejor para el enfermo y se reflejará en la confianza y gratitud del propietario del animal.

\section{REFERENCIAS}

1. Aresu L, Zanatta R, Pregel P, Caliari D, Tursi M, Valenza F, Tarducci A. 2009. Bilateral juvenile renal dysplasia in a Norwegian Forest Cat. J Feline Med Surg 11: 326-329.

2. Bedford JJ, Weggery S, Ellis G, McDonald FJ, Joyce PR, Leader JP, Walker RJ. 2008. Lithium-induced nephrogenic diabetes insipidus: renal effects of amiloride. Clin J Am Soc Nephrol 3: 1324-1331.

3. Braun U, Gansohr B, Seidel M, Dumelin J, Wenger B, Schade B, Pospischil A. 2008. Diabetes mellitus type 1 in a goat. Schweiz Arch Tierheilkd 150: 608-612.

4. Brown CA, Jeong KS, Poppenga RH. 2007. Outbreaks of renal failure associated with melamine and cyanuric acid 
in dogs and cats in 2004 and 2007. J Vet Diagn Invest 19: 525-531.

5. Bush BM. 1996. Interpretation of laboratory results for small animal clinicians, Blackwell, Oxford, $315 \mathrm{p}$.

6. Cao HY, Wu QH, Huang P, He JY. 2009. Impacts of the formula of Suoquanwan (SQW) on expression of AQP-2 mRNA and AVPR-V2 mRNA in the kidney of rat polyuria model of Yang-deficiency. Zhong Yao Cai 32: 926928.

7. Chiaramonte D, Greco DS. 2007. Feline adrenal disorders. Clin Tech Small Anim Pract 22: 26-31.

8. Cianciolo RE, Bischoff K, Ebel JG, Van Winkle TJ, Goldstein RE, Serfilippi LM. 2008. Clinicopathologic, histologic, and toxicologic findings in 70 cats inadvertently exposed to pet food contaminated with melamine and cyanuric acid. J Am Vet Med Assoc 233: 1229-1231.

9. Coles EH. 1989. Veterinary clinical pathology, 4th ed., Saunders, Philadelphia, $486 \mathrm{p}$.

10. Coppo JA, Sandoval GL, Scorza SH, Pochon DO, Mussart NB, Koscinczuk P. 1991. Correlation between plasmatic electrolyte imbalances and electrocardiogram in ethylene-glycol experimentally intoxicated dogs. Veterinaria 3: 41-53.

11. Coppo JA, Mussart NB, Slanac AL. 1997. Modificaciones bioquímicas registradas en perros intoxicados con vitamina D. Pet's Ciencia 13: 97-106.

12. Coppo JA, Mussart NB. 2003. Apoyatura bioquímica al diagnóstico veterinario. Casuística registrada tras 25 años de funcionamiento de un servicio de análisis clínicos. Rev Vet 11: 34-39.

13. Coppo JA. 2008. Fisiología comparada del medio interno, EUCASA, Salta, 310 p.

14. Coppo JA. 2008. Acuaporinas. Rev Vet 19: 167-178.

15. Coppo JA. 2010. Interpretación de análisis clínicos en perros y gatos, EUCASA, Salta, $350 \mathrm{p}$.

16. Duncan JR, Prasse KW. 1985. Examen clínico de la orina. En: El laboratorio en medicina veterinaria (Tasker JB ed.), Hemisferio Sur, Buenos Aires, 292 p.

17. Feldman EC, Nelson RW. 1989. Diagnostic approach to polydipsia and polyuria. Vet Clin North Am Small Anim Pract 19: 327-341.

18. Greco DS. 2006. Pediatric endocrinology. Vet Clin North Am Small Anim Pract 36: 549-556.

19. Green RA. 1998. Perspectives of clinical osmometry. Vet Clin North Am 8: 287-299.

20. Hardy RM, Osborne CA. 1984. Síndromes poliúricos. En: Terapéutica veterinaria (Kirk RW ed.), Continental, México, p. 1060-1064.

21. Hostutler RA, Chew DJ, Jaeger JQ, Klein S, Henderson D, DiBartola SP. 2005. Uses and effectiveness of pamidronate disodium for treatment of dogs and cats with hypercalcemia. J Vet Intern Med 19: 29-33.

22. Kaft W. 1992. Diagnostic procedure in polydipsia. Tierarztl Prax 20: 460-461.

23. Kirsch M. 1998. Incidence of bacterial cystitis in diabetic dogs and cats at the time of diagnosis. Tierarztl Prax Ausg K Klientiere Emitiere 26: 32-36.

24. Kong J, Zhang Z, Li D, Wong KE, Zhang Y, Szeto FL, Musch MW, Li YC. 2008. Loss of vitamin D receptor produces polyuria by increasing thirst. J Am Soc Nephrol 19: 2396-2405.

25. Kutina AV, Zakharov VV, Natochin YV. 2008. Excretion of proteins by rat kidney during various types of diuresis. Bull Exp Biol Med 146: 671-674.

26. Meyer DJ. 2000. El laboratorio en medicina veterinaria, $2^{\circ}$ ed., Inter-Médica, Buenos Aires, 397 p.

27. Nelson RW, Couto CG. 2000. Medicina interna de animales pequeños, $2^{\circ}$ ed., Inter-Médica, Buenos Aires, p. 630-636.

28. Nichols R. 1990. Polyuria and polydipsia. Problems associated with patient evaluation. Probl Vet Med 2: 610-616.

29. Planellas Bachs M. 2008. Poliuria-polidipsia. Publ. Hosp. Clín. Fac. Veterinaria Barcelona, http://minnie.uab. es/ veteri/21233/Classe\%20de\%20MI\%2024M.pdf.

30. Polzin DJ, Osborne CA. 1995. Pathophysiology of renal failure and uremia. In: Canine and feline nephrology and urology (Osborne CA, Finco DR ed.), William \& Wilkins, Baltimore, p. 335.

31. Quante S, Sieber-Ruckstuhl N, Wilhelm S, Favrot C, Dennler M, Reusch C. 2009. Hyperprogesteronism due to bilateral adrenal carcinomas in a cat with diabetes mellitus. Schweiz Arch Tierheilkd 151: 437-442.

32. Renkema KY, Velic A, Dijkman HB. 2009. The calciumsensing receptor promotes urinary acidification to prevent nephrolithiasis. J Am Soc Nephrol 20: 1705-1713.

33. Schaer M. 1991. Fluidoterapia y alteraciones electroliticas, Inter-Vet, Buenos Aires, 224 p.

34. Schrier RW. 2009. Interactions between angiotensin II and arginine vasopressin in water homeostasis. Kidney Int 76:137-139.

35. Shiel RE, Pinilla M, Mooney CT. 2009. Syndrome of inappropriate antidiuretic hormone secretion associated with congenital hydrocephalus in a dog. J Am Anim Hosp Assoc 45: 249-252.

36. Sociedad Argentina de Terapia Intensiva-SATI. 2006. Poliurias. Diagnósticos diferenciales y enfoque terapéutico. http://www.sati.org.ar/interior.php.

37. Sodikoff CH. 1995. Laboratory profiles of small animal diseases, 2nd ed., Mosby, Baltimore, $434 \mathrm{p}$.

38. Suga H, Nagasaki H, Kondo TA. 2008. Novel treatment for lithium-induced nephrogenic diabetes insipidus rat model using the Sendai-virus vector carrying aquaporin 2 gene. Endocrinology 149: 5803-5810.

39. Swann HM, Brown DC. 2001. Hepatic lobe torsion in 3 dogs and a cat. Vet Surg 30: 482-486.

40. Tonomura Y, Yamamoto E, Kondo C, Itoh A, Tsuchiya N, Uehara T, Baba T. 2009. Amphotericin B-induced nephrotoxicity: characterization of blood and urinary biochemistry and renal morphology in mice. Hum Exp Toxicol 28: 293-300.

41. Vonderen IK. 2004. The role of vasopressin in dogs with polyuria. Tijdschr Diergeneeskd 129: 751-755.

42. Wang S, Mitu GM, Hirschberg R. 2008. Osmotic polyuria: an overlooked mechanism in diabetic nephropathy. Nephrol Dial Transplant 23: 2167-2172.

43. Willard MD. 2002. Small animal clinical diagnosis by laboratory methods, Saunders, Philadelphia, $406 \mathrm{p}$. 